\title{
Clinical Study \\ Relation between Gastric Cancer and Protein Oxidation, DNA Damage, and Lipid Peroxidation
}

\author{
Yongsheng Ma, ${ }^{1}$ Lin Zhang, ${ }^{1}$ Shengzhong Rong, ${ }^{2}$ Hongyan Qu, ${ }^{3}$ Yannan Zhang, \\ Dong Chang, ${ }^{1}$ Hongzhi Pan, ${ }^{4}$ and Wenbo Wang ${ }^{1}$ \\ ${ }^{1}$ The First Affiliated Hospital of Harbin Medical University, No. 199 Dongdazhi Street, Nangang District, Harbin, \\ Heilongjiang 150001, China \\ ${ }^{2}$ Public Health School, Mudanjiang Medical College, No. 3 Tongxiang Street, Aimin District, Mudanjiang, Heilongjiang 157011, China \\ ${ }^{3}$ The Third Affiliated Hospital of Harbin Medical University, No. 150 Haping Road, Nangang District, Harbin, \\ Heilongjiang 150081, China \\ ${ }^{4}$ Public Health School, Harbin Medical University, No. 157 Baojian Road, Nangang District, Harbin, Heilongjiang 150081, China
}

Correspondence should be addressed to Hongzhi Pan; panhongzhilaoshi@163.com and Wenbo Wang; 949439265@qq.com

Received 28 August 2013; Revised 29 October 2013; Accepted 1 December 2013

Academic Editor: Neelam Khaper

Copyright (C) 2013 Yongsheng Ma et al. This is an open access article distributed under the Creative Commons Attribution License, which permits unrestricted use, distribution, and reproduction in any medium, provided the original work is properly cited.

Objects. The aim of this study is to evaluate protein oxidation, DNA damage, and lipid peroxidation in patients with gastric cancer and to investigate the relationship between oxidative stress and gastric cancer. Methods. We investigated changes in serum protein carbonyl (PC), advanced oxidation protein products (AOPP), and 3-nitrotyrosine (3-NT) levels, as indicators of protein oxidation, serum 8-hydroxydeoxyguanosine (8-OHdG), as a biomarker of DNA damage, and malondialdehyde (MDA), conjugated diene (CD), 4-hydroxynonenal (4-HNE), and 8-ISO-prostaglandin $\mathrm{F}_{2 \alpha}$ (8-PGF) in serum, as lipid peroxidation markers in gastric cancer (GC) patients and healthy control. Results. Compared with control, a statistically significant higher values of 8-OHdG, PC, AOPP, and 3-NT were observed in the GC patients $(P<0.05)$. The products of lipid peroxidation, MDA, CD, 4-HNE, and 8-PGF, were significantly lower in the GC patients compared to those of control $(P<0.05)$. In addition, the products of oxidative stress were similar between the Helicobacter pylori positive and the negative subgroups of GC patients. Conclusions. GC patients were characterized by increased protein oxidation and DNA damage, and decreased lipid peroxidation. Assessment of oxidative stress and augmentation of the antioxidant defense system may be important for the treatment and prevention of gastric carcinogenesis.

\section{Introduction}

Gastric cancer (GC) is one of the most frequent diseases in human population. It is the fourth frequent cancer and the second most common cause of deaths from cancer in the world, accounting for a large proportion of cancer cases in China in recent years [1]. The pathogenesis of GC is not understood completely. Nutritional, microbial, and genetic factors acting in a multistep and multifactorial process have been proposed [2], where oxidative stress was involved in the possible mechanisms of GC development.

Reactive oxygen species (ROS) are the normal product of a variety of essential biochemical reactions and the generation of ROS is an unavoidable consequence of aerobic life.
Normal level of ROS has physiological functions, whereas it is toxic to the cells at high level. Overproduction of ROS through either endogenous or exogenous insults is harmful to living organisms and is termed oxidative stress [3].

Oxidative stress can damage cellular macromolecules, leading to DNA and protein modification and lipid peroxidation [4]. Oxidative stress produced by free radicals has been associated with the development of several diseases such as cardiovascular, cancer, and chronic inflammation [37]. It is also known that ROS could be excessively formed in chronic diseases of the gastrointestinal tract and toxic to normal cells, which might contribute to the increased risk of cancer $[6,7]$, but the precise mechanisms are still remaining to be elucidated. 
The aim of this study is to investigate the relationship between oxidative stress and GC. We used spectrophotometric assay and enzyme-linked immunosorbent assay (ELISA) to detect the levels of lipid peroxidation products such as malondialdehyde (MDA), conjugated dienes (CD), 4hydroxynonenal (4-HNE), and 8-Iso-prostaglandin $\mathrm{F}_{2 \alpha}$ (8PGF) and measured the concentration of protein damage products including advanced oxidation protein products (AOPP), protein carbonyl (PC), and 3-nitrotyrosine (3-NT) in patients with gastric cancer and healthy control subjects. In addition, we determined 8-hydroxydeoxyguanosine (8OHdG) content, the DNA damage produced in GC patients, and healthy control, too. In the present study, we provide evidence for the first time indicating the relationship between protein carbonyl and the risk of gastric cancer.

\section{Material and Methods}

2.1. Subjects. This is an age-and sex-matched case-control study. Thirty patients with newly diagnosed GC are recruited for the experiment group, among whom 17 patients were positive for Helicobacter pylori $\left(\mathrm{Hp}^{+}\right)$and 13 negative $\left(\mathrm{HP}^{-}\right)$. Diagnosis of gastric cancer was confirmed by histopathological examination and histopathology. Tumors were classified according to their predominant histological pattern into intestinal $(n=13)$, diffuse $(n=6)$, and adenocarcinoma $(n=11)$. The pathologic stage $(\mathrm{TNM})$ was determined according to the newly revised classification of the American Joint Committee on Cancer (AJCC) and the International Union Against Cancer (UICC). Seven patients had AJCC Stage II tumors, and ten patients had AJCC Stage III tumors. The remaining thirteen patients had UICC Stage III or IV gastric adenocarcinoma. Urease test and histopathologic examination were carried out to determine the infection of Helicobacter pylori (HP). If the urease test and histology were positive, the diagnosis of HP infection was confirmed. If both tests were negative, the patient was considered $\mathrm{Hp}^{-}$. Exclusion criteria included subjects who had been taking antioxidant supplements and regularly used acetylsalicylic acid and other nonsteroidal anti-inflammatory drugs. Other exclusion criteria included diabetes mellitus, hypertension, arteriosclerosis, severe liver disease, cataract, renal failure, and dialysis. All patients were recruited from the Third Affiliated Hospital of the Harbin Medical University. Both groups belonged to the same ethnic group.

Thirty healthy, age-matched subjects, who came to the same hospital for an annual checkup, were also included as controls. The control subjects were in good health, as determined by a medical history questionnaire, physical examination, and normal results of clinical laboratory tests. None of the control subjects were taking any medication. All subjects gave written informed consent to participate in this study.

2.2. Blood Sampling. Venous peripheral blood samples $(10 \mathrm{~mL})$ were collected from each subject after $12 \mathrm{~h}$ of overnight fasting. The samples were placed on ice and centrifuged at $3500 \mathrm{rpm}$ and $4^{\circ} \mathrm{C}$ for $15 \mathrm{~min}$, and the supernatants were stored at $-80^{\circ} \mathrm{C}$ and determination was accomplished within
3 months. All samples from each patient were run in the same assay.

2.3. Laboratory Analysis. AOPP were quantified as described by Witko-Sarsat et al. [8]. PC concentrations in plasma were measured with spectrophotometric assay described by Reznick and Packer [9]. CD and MDA were measured by spectrophotometric assay [4]. Serum 8-OHdG was measured with ELISA method following the maker's instructions (Highly Sensitive 8-OHdG Check, Japan Institute for the Control of Aging, Fukuroi, Shizuoka). 3-NT (Hycult Biotechnology B.V.), 4-HNE, and 8-PGF (Cell Biolabs, Inc.) were measured with ELISA following the maker's instructions. Briefly, $50-100 \mu \mathrm{L}$ of serum was added into each well of the microtiter plate and incubated for $2 \mathrm{~h}$ at $37^{\circ} \mathrm{C}$. Secondary antibody was added to the plate and incubated at $37^{\circ} \mathrm{C}$ for $1 \mathrm{~h}$, the unbound enzyme-labeled secondary antibody was removed, and then the antibodies binding with the plate were identified using a substrate that contained $3,3^{\prime}, 5,5^{\prime}$ tetramethylbenzidine. Absorbance was measured using a spectrophotometric plate reader (BIO-RAD) at wavelength of $450 \mathrm{~nm}$. Quantification of the 8-OHdG, 3-NT, 8-PGF, and 4HNE were done by comparing the optical densities of each sample to that of an internal standard known at various concentrations.

2.4. Other Biochemical Parameters. Blood glucose, triglycerides, and cholesterol were determined using routine clinical chemical assays.

2.5. Statistical Analysis. Data are presented as mean \pm SD. All experimental data in this study were statistically analyzed with SAS 9.13. The statistical significance was evaluated using unpaired Student's $t$-test. Results were considered significant when $P<0.05$.

\section{Results}

3.1. Baseline Characteristics. The clinical characteristics of the GC patients and control subjects are shown in Table 1. Age and gender of the patients were not significantly different from those of the controls. Initial clinical laboratory test values, such as glucose, cholesterol, triglycerides, and blood pressure, were also not significantly different between the two groups. What is more, all the test values were in normal range.

\subsection{Results of Protein Oxidative Damage and DNA Damage} Products in Serum. As shown in Table 2, the concentration of AOPP in GC patients was increased significantly than that of control $(25.75 \pm 5.75$ versus $22.29 \pm 5.27 ; P<0.05)$. Serum 3-NT also significantly increased in GC patients compared with normal subjects $(117.75 \pm 37.12$ versus $92.85 \pm 14.47$, $P<0.01)$; so was serum PC $(2.16 \pm 0.68$ versus $1.73 \pm 0.75$; $P<0.05)$ and serum $8-\mathrm{OHdG}(16.34 \pm 8.30 \mathrm{ng} / \mathrm{mL}$ versus $12.29 \pm 5.72 \mathrm{ng} / \mathrm{mL}, P<0.05)$.

3.3. Results of Products of Lipid Peroxidation in Serum. As shown in Table 3, there was a significant decrease in serum 
TABLE 1: Demographic and clinical characteristics of patients and controls.

\begin{tabular}{lcc}
\hline Factors & Control & Patients \\
\hline$N$ & 30 & 30 \\
Age (years) & $62.5 \pm 8.4$ & $61.4 \pm 7.7$ \\
Sex (F/M) & $17 / 13$ & $19 / 11$ \\
Cholesterol (mmol/L) & $4.92 \pm 0.63$ & $5.06 \pm 0.68$ \\
Triglycerides (mmol/L) & $1.06 \pm 0.33$ & $1.13 \pm 0.41$ \\
Glucose (mmol/L) & $4.62 \pm 0.87$ & $4.56 \pm 0.65$ \\
Systolic blood pressure (mmHg) & $124.5 \pm 9.0$ & $124.7 \pm 9.3$ \\
Diastolic blood pressure (mmHg) & $76.5 \pm 6.6$ & $77.8 \pm 7.3$ \\
Smoking habit & & \\
$\quad$ Current smokers & 8 & 6 \\
$\quad$ Nonsmokers & 16 & 14 \\
$\quad$ Ex-smokers & 6 & 10 \\
Alcohol intake (Y/N) & $16 / 14$ & $17 / 13$ \\
Physical exercise $(\mathrm{Y} / \mathrm{N})$ & $18 / 12$ & $10 / 20$ \\
History of family $(\mathrm{Y} / \mathrm{N})$ & & $6 / 24$ \\
\hline
\end{tabular}

Data are means \pm SD.

MDA in cancer patients $(5.07 \pm 1.89 \mathrm{nmol} / \mathrm{mL})$ compared with normal subjects $(6.32 \pm 1.88 \mathrm{nmol} / \mathrm{mL}, P<0.05)$. Serum conjugated dienes in cancer patients have also a significant decrease than those in controls $(0.534 \pm 0.239$ versus $0.739 \pm$ $0.239, P<0.01)$. So was $4-\mathrm{HNE}(13.93 \pm 7.50$ versus $18.13 \pm$ $7.95, P<0.05)$ and 8 -PGF $(30.11 \pm 12.65$ versus $38.32 \pm 10.82$; $P<0.01)$.

3.4. Results of Oxidative Stress Products in Helicobacter Pylori Infection Positive and Negative Subgroups. We divided the 30 patients into 2 groups according to HP infection. As shown in Table 4, products of oxidative stress were similar between the HP infection positive and negative subgroups of the gastric cancer patients $(P>0.05)$.

\section{Discussion}

Gastric carcinoma is one of the most common neoplasms in the world. There are a lot of pathological factors, such as ROS, involved in the process of cancer initiation and progression, as evidenced by the fact that oxidative stress plays an important role in the molecular mechanism of gastric cancer $[3,4,6,7]$. Exposure of proteins to reactive oxygen or nitrogen species results in modification of amino acid residues, altering the protein structure and function $[10,11]$. Biomarkers of protein oxidation are often applied when a battery of markers of oxidative stress status is being studied. In this study, we detected the contents of PC, AOPP, and 3-NT, which have been applied as biomarkers of protein oxidation. Although proteins are major targets for oxidative and nitrative damage in vivo, it is widely recognized that oxidation of proteins plays an essential role in the pathogenesis of cancers [10].

Oxidation of proteins can lead to the formation of oxidized amino acids and altered amino acid side chains containing reactive carbonyls [12]. The major product of peroxynitrite attack on proteins is an addition of a nitro group to the orthoposition of tyrosine residues to produce nitrotyrosine. 3-NT has been used as a biomarker of nitrative damage in vivo $[13,14]$. The presence of $3-\mathrm{NT}$ in some carcinomas was previously reported [15]. In our study, serum 3-NT level was significantly higher in the GC patients. This result is constant with other researchers' findings. Goto et al. [16] and Bancel et al. [17] found that 3-NT levels are elevated in gastric cancer patients.

Protein carbonyl is the most popular biomarker for severe oxidative protein damage [18]. It can be generated through oxidative cleavage of proteins by either the $\alpha$-amidation pathway or by oxidation of glutamyl side chains, leading to the formation of a peptide in which the N-terminal amino acid is blocked by an $\alpha$-ketoacyl derivative [10]. The previous studies showed that cancer patients have higher levels of PC $[4,19]$. But Hoque et al. found that there was no significant change in prostate cancer patients of serum PC in a large nested case-control study [20]. In this study, we found increased PC levels in gastric cancer. Our results show that $\mathrm{PC}$ is a potential biomarker available for assessing oxidative stress in gastric cancer.

AOPP, products of the action of free radicals on proteins, were described by Witko-Sarsat et al. [8] for the first time. AOPP is defined as dityrosine containing cross-linked protein products and are considered to be reliable biomarkers to estimate the degree of protein oxidation [21]. They are elevated in patients with renal insufficiency and they reach the highest levels in patients after renal replacement therapy [22]. Increased levels were also found in cancer patients where they correlated with markers of oxidative stress [23, 24]. We found that the level of AOPP was significantly higher in GC patients. In accordance with our findings, Noyan et al. [25] showed that AOPP concentration was significantly higher in the serum specimens from gastric cancer than those from the normal control.

In the present study, we have determined the protein oxidation products of 3-NT, AOPP, and PC. All the protein oxidation products were significantly higher in GC patients. This means that there was severe protein oxidation damage in gastric cancer patients.

ROS can cause strand breaks and base modifications in DNA. For example, oxidation of guanine residues to 8-OHdG is an oxidized nucleoside of DNA that is the most frequently detected and studied DNA lesion. It has been regarded as a novel biomarker for oxidative DNA damage in vivo and appears to play a crucial role in mutagenesis. Elevated levels of 8-OHdG were demonstrated in some carcinomas, including gastric cancer [15, 26-28]. Farinati et al. [27] and Hahm et al. [28] showed a significant increase of 8-OHdG in HPpositive and -negative gastric cancer patients. Interestingly, the levels of 8-OHdG in gastric mucosa have been shown to decrease substantially after the eradication of HP infection. In our research we also found that there was increased serum 8-OHdG in gastric cancer. Nevertheless, the greater oxidative DNA damage in the GC, as a possible result of impaired antioxidant activity, implies an important role for oxygen free radicals in stomach carcinogenesis. Therefore, the contents of 
TABLE 2: Serum levels of protein oxidation and DNA damage products.

\begin{tabular}{lcccc}
\hline Group & AOPP $(\mu \mathrm{mol} / \mathrm{mL})$ & 3-NT $(\mathrm{ng} / \mathrm{mL})$ & Protein carbonyl $(\mathrm{nmol} / \mathrm{mL})$ & $8-\mathrm{OHdG}(\mathrm{ng} / \mathrm{mL})$ \\
\hline Control & $22.29 \pm 5.27$ & $92.85 \pm 14.47$ & $1.73 \pm 0.75$ & $12.29 \pm 5.72$ \\
Patients & $25.75 \pm 5.75^{*}$ & $117.75 \pm 37.12^{* *}$ & $2.16 \pm 0.68^{*}$ & $16.34 \pm 8.30^{*}$ \\
\hline
\end{tabular}

Data are means $\pm \mathrm{SD} .{ }^{*} P<0.05$ compared to controls, ${ }^{* *} P<0.01$ versus healthy subject.

TABLE 3: Serum levels of lipid peroxidation products.

\begin{tabular}{lcccc}
\hline Group & MDA $(\mathrm{nmol} / \mathrm{mL})$ & $8-\mathrm{PGF}(\mathrm{pg} / \mathrm{mL})$ & $4-\mathrm{HNE}(\mathrm{nmol} / \mathrm{mL})$ & $\mathrm{CD}(\mathrm{OD}, 233 \mathrm{~nm})$ \\
\hline Control & $6.32 \pm 1.88$ & $38.32 \pm 10.82$ & $18.13 \pm 7.95$ & $0.739 \pm 0.239$ \\
Patients & $5.07 \pm 1.89^{*}$ & $30.11 \pm 12.65^{* *}$ & $13.93 \pm 7.50^{*}$ & $0.534 \pm 0.233^{* *}$ \\
\hline
\end{tabular}

Data are means $\pm \mathrm{SD} .{ }^{*} P<0.05$ versus healthy subject, ${ }^{* *} P<0.01$ versus healthy subject.

TABLE 4: The results of oxidative stress products in H. pylori infection patients.

\begin{tabular}{lcc}
\hline & $\begin{array}{c}\text { HP infection } \\
\text { Negative }\left(\mathrm{Hp}^{-}\right)\end{array}$ & $\begin{array}{c}\text { HP infection } \\
\text { Positive }\left(\mathrm{Hp}^{+}\right)\end{array}$ \\
\hline$n$ & 13 & 17 \\
MDA $(\mathrm{nmol} / \mathrm{mL})$ & $4.90 \pm 1.49$ & $5.20 \pm 2.18$ \\
CD $(\mathrm{OD}, 233 \mathrm{~nm})$ & $0.551 \pm 0.192$ & $0.521 \pm 0.265$ \\
$4-\mathrm{HNE}(\mathrm{nmol} / \mathrm{mL})$ & $14.65 \pm 9.84$ & $13.37 \pm 5.35$ \\
8-PGF $(\mathrm{pg} / \mathrm{mL})$ & $28.74 \pm 8.11$ & $31.15 \pm 15.43$ \\
AOPP $(\mu \mathrm{mol} / \mathrm{mL})$ & $25.99 \pm 6.01$ & $25.56 \pm 5.72$ \\
PC $(\mathrm{nmol} / \mathrm{mL})$ & $2.13 \pm 0.81$ & $2.18 \pm 0.58$ \\
3-NT $(\mathrm{ng} / \mathrm{mL})$ & $114.49 \pm 44.56$ & $120.25 \pm 31.51$ \\
8-OHdG $(\mathrm{ng} / \mathrm{mL})$ & $15.36 \pm 7.72$ & $17.09 \pm 8.88$ \\
\hline
\end{tabular}

Data are means \pm SD.

8-OHdG in serum could act as a sensitive biomarker for GC patients, too.

Lipid peroxidation is initiated by free radical attack on membrane lipids, generating large amounts of reactive products, which have been implicated in tumor initiation and promotion. In this study, we selected a series of products of lipid peroxidation, MDA, CD, 8-PGF, and 4-HNE, which are widely used, sensitive, and applicable for large scale studies.

MDA is a product of the breakdown of mainly unsaturated fatty acids into their essential chains through oxidation, which is the most studied free radical reaction. But the data reported in the literature on MDA levels in different human cancer types remains controversial. Some researchers reported that lipid peroxidation increased and MDA level advanced in cancer patients. Arivazhagan et al. [29] reported increased erythrocyte MDA levels in patients with gastric cancer. Khanzode et al. [30] and Bakan et al. [31] reported increased plasma MDA levels in gastric cancer patients compared with those in control subjects. However, some other reports are not consistent with these findings. Punnonen et al. [32] found increased serum MDA levels but decreased tissue MDA levels in human breast cancer. Chang et al. [4] and Biasi et al. [33] reported decreased serum MDA levels in human colon cancer. Murugan et al. [34] reported significantly decreased serum MDA levels in N-methyl- $\mathrm{N}^{\prime}$ nitro-N-nitrosoguanidine (MNNG)-induced gastric carcinogenesis in rat model. Inconsistent with some but consistent with other findings, our results show a decrease of serum MDA levels in patients compared with those in control subjects $[30,31]$.

$\mathrm{CD}$ is the initial formation of the lipid peroxide. Murugan et al. [34] reported significantly decreased serum CD levels in MNNG-induced gastric cancer in rats. Chang et al. [4] revealed significantly decreased serum CD levels in colorectal cancer patients. 4 -HNE is the major $\alpha, \beta$-unsaturated aldehydes produced by membrane lipid peroxidation, and it can be a potential indicator of lipid peroxidation. Murugan et al. [34] also reported significantly decreased serum 4-HNE levels in MNNG-induced gastric carcinogenesis in rat model. In the present study, we found that there were decreased $\mathrm{CD}$ and 4-HNE in serum in GC patients compared with control subjects.

The prostaglandin, 8-PGF, is an isoprostane that is produced by the nonenzymatic peroxidation of arachidonic acid in membrane phospholipids [35]. 8-PGF is a major isoprostane that is chemically stable and measurable in biofluids, and is a reliable biomarker for assessing the rate of lipid peroxidation of subjects Other than the widely appreciated biomarker, Camphausen et al. [36] found it unattainable to detect an increased 8-PGF in the urine of patients with prostate cancer compared with normal controls. We found that the level of 8-PGF was significantly lower compared with control. As far as we know, our study represents the first report to test the relationship between serum 8-PGF, and the risk of gastric cancer.

Considering that there are some contradictory results of lipid peroxidation reported in cancer, in this study we select a series of different products of lipid peroxidation, including MDA, CD, 4-HNE, and 8-PGF, to investigate the relationship between GC and lipid peroxidation. We found, for the first time, the lipid peroxidation products prone to the same declining trend, with all the products of lipid peroxidation being decreased significantly in serum of gastric cancer patients compared to healthy control. We propose that the decreased levels of MDA, CD, 4-HNE and 8-PGF in GC patients may relate to tumor aggressiveness which is in line with the hypothesis proposed by Slater et al. [37], who assumed that rapidly dividing cells tend to set an oxidantantioxidant status favorable to their growth. Rapidly proliferating tumor cells show resistance to lipid peroxidation and overexpress antioxidant enzymes. Peroxidation is deleterious 
for cell proliferation through the production of reactive oxygen species, with the exact mechanism remaining unraveled. Further studies are needed to conclusively determinate the correlation between the lipid peroxidation and cancer.

Helicobacter pylori related gastritis is characterized by increased free radical production and peroxidative damage $[38,39]$. Production of ROS by gastric cells and phagocytes induced by HP has been shown in vitro, and increased levels of ROS in the gastric mucosa have been verified in HPinfected patients $[40,41]$. A positive association has been demonstrated between HP infection and gastric adenocarcinoma with increased oxidative stress [42].

We therefore investigated whether HP infection was also related to a progressive accumulation of oxidative mutagenic events that could play a major role in gastric carcinogenesis. The 8-OHdG levels were significantly higher in GC than in the control group, but significant difference was not detected between HP-positive and -negative samples in spite of slightly higher 8-OHdG levels in the HP-positive GC patients. The result is in line with the findings of Farinati et al. [43] and Noyan et al. [25], where the level of AOPP was increased significantly in the gastric cancer patients as compared with nongastric cancer patients. However, there were no significant differences between the anti-HP IgG positive and negative patients with gastric cancer. And we also found that the level of AOPP was not significantly different between the HP-positive and -negative gastric cancer patients. Goto et al. [16] demonstrated that 3-NT in the gastric mucosa was significantly higher in the HP-positive group than in the HPnegative group. But our results showed that there was no significant difference in oxidative stress parameters between the HP-positive and -negative gastric cancer patients. These contradictory results suggest that the relationship between $\mathrm{HP}$ infection and gastric adenocarcinoma with increased oxidative stress still remains unclear. Although approximately half of the world population are infected with HP, a cancerous outcome of infection is very rare. Hence, whether HP infection is a major causative factor for GC remains questionable according to the discrepancies among the current literature.

\section{Conclusions}

In summary, the results obtained here confirm that oxidative stress is involved in gastric cancer, though there was no significant difference in oxidative stress parameters between the HP-positive and -negative gastric cancer patients. We found that the gastric cancer patients had increased levels of protein oxidation and DNA damage versus control subjects, but decreased lipid peroxidation products. The mechanism remains to be fully revealed. It would be worthwhile to further study the correlation between these biomarkers and levels of lipid peroxidation and GC. Assessment of oxidative stress and augmentation of the antioxidant defense systems may be important for the treatment and prevention of gastric cancer.

\section{Authors' Contribution}

Yongsheng Ma and Lin Zhang contributed equally to this work.

\section{Acknowledgment}

This study was supported by the Heilongjiang Province Postdoctoral Foundation Grant LBH-Z10075.

\section{References}

[1] D. M. Parkin, F. Bray, J. Ferlay, and P. Pisani, "Global cancer statistics, 2002," Cancer Journal for Clinicians, vol. 55, no. 2, pp. 74-108, 2005.

[2] P. Correa, "A new paradigm for human gastric carcinogenesis," Journal of Clinical Gastroenterology, vol. 30, pp. 381-385, 2000.

[3] M. Valko, C. J. Rhodes, J. Moncol, M. Izakovic, and M. Mazur, "Free radicals, metals and antioxidants in oxidative stressinduced cancer," Chemico-Biological Interactions, vol. 160, no. 1, pp. 1-40, 2006.

[4] D. Chang, F. Wang, Y.-S. Zhao, and H.-Z. Pan, "Evaluation of oxidative stress in colorectal cancer patients," Biomedical and Environmental Sciences, vol. 21, no. 4, pp. 286-289, 2008.

[5] T. D. Oberley, "Oxidative damage and cancer," American Journal of Pathology, vol. 160, no. 2, pp. 403-408, 2002.

[6] Y. Lin, S. Kikuchi, Y. Obata, and K. Yagyu, "Serum copper/zinc superoxide dismutase $(\mathrm{Cu} / \mathrm{Zn} \mathrm{SOD})$ and gastric cancer risk: a case-control study," Japanese Journal of Cancer Research, vol. 93, no. 10, pp. 1071-1075, 2002.

[7] M. Yasuda, F. Takesue, S. Inutsuka, M. Honda, T. Nozoe, and D. Korenaga, "Prognostic significance of serum superoxide dismutase activity in patients with gastric cancer," Gastric Cancer, vol. 5, no. 3, pp. 148-153, 2002.

[8] V. Witko-Sarsat, M. Friedlander, C. Capeillère-Blandin et al., "Advanced oxidation protein products as a novel marker of oxidative stress in uremia," Kidney International, vol. 49, no. 5, pp. 1304-1313, 1996.

[9] A. Z. Reznick and L. Packer, "Oxidative damage to proteins: spectrophotometric method for carbonyl assay," Methods in Enzymology, vol. 233, pp. 357-363, 1994.

[10] B. S. Berlett and E. R. Stadtman, "Protein oxidation in aging, disease, and oxidative stress," The Journal of Biological Chemistry, vol. 272, no. 33, pp. 20313-20316, 1997.

[11] E. R. Stadtman and B. S. Berlett, "Reactive oxygen-mediated protein oxidation in aging and disease," Drug Metabolism Reviews, vol. 30, no. 2, pp. 225-243, 1998.

[12] S. Adams, P. Green, R. Claxton et al., "Reactive carbonyl formation by oxidative and non-oxidative pathways," Frontiers in Bioscience A, vol. 6, pp. 17-24, 2001.

[13] B. Halliwell, "What nitrates tyrosine? Is nitrotyrosine specific as a biomarker of peroxynitrite formation in vivo," FEBS Letters, vol. 411, no. 2-3, pp. 157-160, 1997.

[14] H. Ohshima, M. Friesen, I. Brouet, and H. Bartsch, "Nitrotyrosine as a new marker for endogenous nitrosation and nitration of proteins," Food and Chemical Toxicology, vol. 28, no. 9, pp. 647-652, 1990

[15] S. Kondo, S. Toyokuni, Y. Iwasa et al., "Persistent oxidative stress in human colorectal carcinoma, but not in adenoma," Free Radical Biology and Medicine, vol. 27, no. 3-4, pp. 401-410, 1999.

[16] T. Goto, K. Haruma, Y. Kitadai et al., "Enhanced expression of inducible nitric oxide synthase and nitrotyrosine in gastric mucosa of gastric cancer patients," Clinical Cancer Research, vol. 5, no. 6, pp. 1411-1415, 1999.

[17] B. Bancel, J. Estève, J.-C. Souquet, S. Toyokuni, H. Ohshima, and B. Pignatelli, "Differences in oxidative stress dependence 
between gastric adenocarcinoma subtypes," World Journal of Gastroenterology, vol. 12, no. 7, pp. 1005-1012, 2006.

[18] I. Dalle-Donne, D. Giustarini, R. Colombo, R. Rossi, and A. Milzani, "Protein carbonylation in human diseases," Trends in Molecular Medicine, vol. 9, no. 4, pp. 169-176, 2003.

[19] F. M. Nathan, V. A. Singh, A. Dhanoa, and U. D. Palanisamy, "Oxidative stress and antioxidant status in primary bone and soft tissue sarcoma," BMC Cancer, vol. 11, article 382, 2011.

[20] A. Hoque, C. B. Ambrosone, C. Till et al., "Serum oxidized protein and prostate cancer risk within the prostate cancer prevention trial," Cancer Prevention Research, vol. 3, no. 4, pp. 478-483, 2010.

[21] C. J. J. Alderman, S. Shah, J. C. Foreman, B. M. Chain, and D. R. Katz, "The role of advanced oxidation protein products in regulation of dendritic cell function," Free Radical Biology and Medicine, vol. 32, no. 5, pp. 377-385, 2002.

[22] V. Witko-Sarsat, M. Friedlander, T. N. Khoa et al., "Advanced oxidation protein products as novel mediators of inflammation and monocyte activation in chronic renal failure," Journal of Immunology, vol. 161, no. 5, pp. 2524-2532, 1998.

[23] F. Kosova, B. Çetin, M. Akinci et al., "Advanced oxidation protein products, ferrous oxidation in xylenol orange, and malondialdehyde levels in thyroid cancer," Annals of Surgical Oncology, vol. 14, no. 9, pp. 2616-2620, 2007.

[24] A. S. Nayyar, M. Khan, K. R. Vijayalakshmi, B. Suman, H. C. Gayitri, and M. Anitha, "Serum total protein, albumin and advanced oxidation protein products (AOPP) - implications in oral squamous cell carcinoma," The Malaysian Journal of Pathology, vol. 34, no. 1, pp. 47-52, 2012.

[25] T. Noyan, H. Guducuoglu, and M. Ilhan, "A study of oxidative stress parameters in anti-helicobacter pylorus immunoglobulin G positive and negative gastric cancer patients," Yonsei Medical Journal, vol. 50, no. 5, pp. 677-682, 2009.

[26] C.-S. Chang, W.-N. Chen, H.-H. Lin, C.-C. Wu, and C.-J. Wang, "Increased oxidative DNA damage, inducible nitric oxide synthase, nuclear factor $\kappa \mathrm{B}$ expression and enhanced antiapoptosis-related proteins in Helicobacter pylori-infected noncardiac gastric adenocarcinoma," World Journal of Gastroenterology, vol. 10, no. 15, pp. 2232-2240, 2004.

[27] F. Farinati, R. Cardin, P. Degan et al., "Oxidative DNA damage accumulation in gastric carcinogenesis," Gut, vol. 42, no. 3, pp. 351-356, 1998.

[28] K. B. Hahm, K. J. Lee, S. Y. Choi et al., "Possibility of chemoprevention by the eradication of Helicobacter pylori: oxidative DNA damage and apoptosis in H. pylori infection," American Journal of Gastroenterology, vol. 92, no. 10, pp. 1853-1857, 1997.

[29] S. Arivazhagan, K. Kavitha, and S. Nagini, "Erythrocyte lipid peroxidation and antioxidants in gastric cancer patients," Cell Biochemistry and Function, vol. 15, no. 1, pp. 15-18, 1997.

[30] S. S. Khanzode, S. D. Khanzode, and G. N. Dakhale, "Serum and plasma concentration of oxidant and antioxidants in patients of Helicobacter pylori gastritis and its correlation with gastric cancer," Cancer Letters, vol. 195, no. 1, pp. 27-31, 2003.

[31] E. Bakan, S. Taysi, M. F. Polat et al., "Nitric oxide levels and lipid peroxidation in plasma of patients with gastric cancer," Japanese Journal of Clinical Oncology, vol. 32, no. 5, pp. 162-166, 2002.

[32] K. Punnonen, M. Ahotupa, K. Asaishi, M. Hyoty, R. Kudo, and R. Punnonen, "Antioxidant enzyme activities and oxidative stress in human breast cancer," Journal of Cancer Research and Clinical Oncology, vol. 120, no. 6, pp. 374-377, 1994.
[33] F. Biasi, L. Tessitore, D. Zanetti et al., "Associated changes of lipid peroxidation and transforming growth factor $\beta 1$ levels in human colon cancer during tumour progression," Gut, vol. 50, no. 3, pp. 361-367, 2002.

[34] R. S. Murugan, K. V. P. C. Mohan, K. Uchida, Y. Hara, D. Prathiba, and S. Nagini, "Modulatory effects of black tea polyphenols on oxidant-antioxidant profile and expression of proliferation, apoptosis, and angiogenesis-associated proteins in the rat forestomach carcinogenesis model," Journal of Gastroenterology, vol. 42, no. 5, pp. 352-361, 2007.

[35] S. Basu, "Fatty acid oxidation and isoprostanes: oxidative strain and oxidative stress," Prostaglandins Leukotrienes and Essential Fatty Acids, vol. 82, no. 4-6, pp. 219-225, 2010.

[36] K. Camphausen, C. Ménard, M. Sproull, E. Goley, S. Basu, and C. N. Coleman, "Isoprostane levels in the urine of patients with prostate cancer receiving radiotherapy are not elevated," International Journal of Radiation Oncology Biology Physics, vol. 58, no. 5, pp. 1536-1539, 2004.

[37] T. F. Slater, K. H. Cheeseman, C. Benedetto et al., "Studies on the hyperplasia ("regeneration") of the rat liver following partial hepatectomy. Changes in lipid peroxidation and general biochemical aspects," Biochemical Journal, vol. 265, no. 1, pp. 51-59, 1990.

[38] G. R. Davies, N. J. Simmonds, T. R. J. Stevens et al., "Helicobacter pylori stimulates antral mucosal reactive oxygen metabolite production in vivo," Gut, vol. 35, no. 2, pp. 179-185, 1994.

[39] F. Farinati, G. D. Libera, R. Cardin et al., "Gastric antioxidant, nitrites, and mucosal lipoperoxidation in chronic gastritis and Helicobacter pylori infection," Journal of Clinical Gastroenterology, vol. 22, no. 4, pp. 275-281, 1996.

[40] N. Ramarao, S. D. Gray-Owen, and T. F. Meyer, "Helicobacter pylori induces but survives the extracellular release of oxygen radicals from professional phagocytes using its catalase activity," Molecular Microbiology, vol. 38, no. 1, pp. 103-113, 2000.

[41] S.-C. Baik, H.-S. Youn, M.-H. Chung et al., "Increased oxidative DNA damage in Helicobacter pylori-infected human gastric mucosa," Cancer Research, vol. 56, no. 6, pp. 1279-1282, 1996.

[42] S. Park, W. S. Kim, U. J. Choi et al., "Amelioration of oxidative stress with ensuing inflammation contributes to chemoprevention of H. pylori-associated gastric carcinogenesis," Antioxidants and Redox Signaling, vol. 6, no. 3, pp. 549-560, 2004.

[43] F. Farinati, R. Cardin, M. Bortolami et al., "Oxidative DNA damage in gastric cancer: CagA status and OGG1 gene polymorphism," International Journal of Cancer, vol. 123, no. 1, pp. 51-55, 2008. 


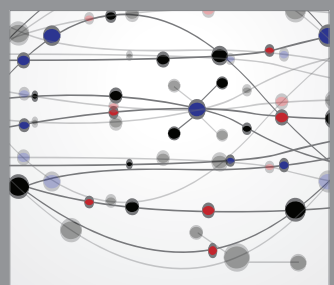

The Scientific World Journal
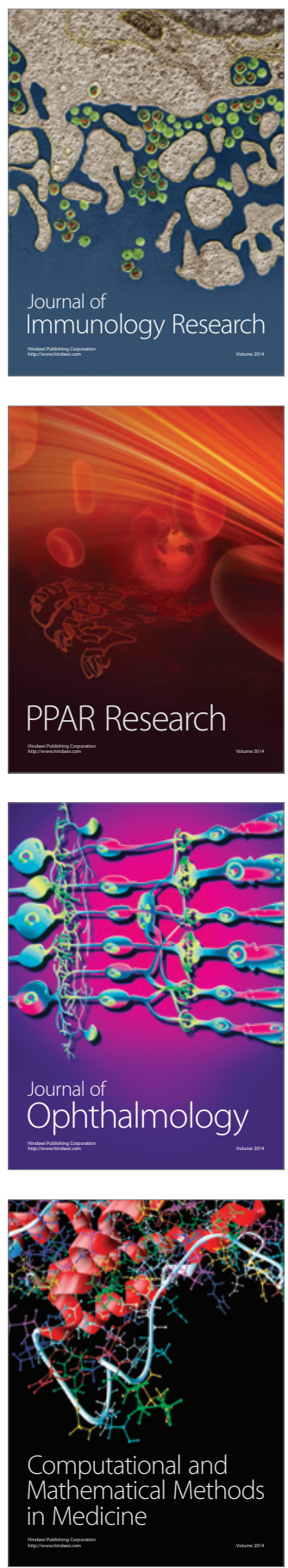

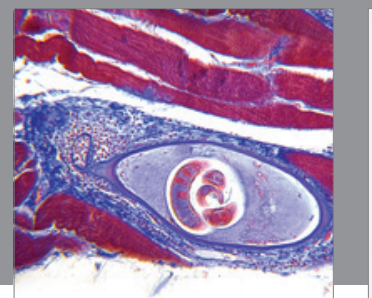

Gastroenterology

Research and Practice
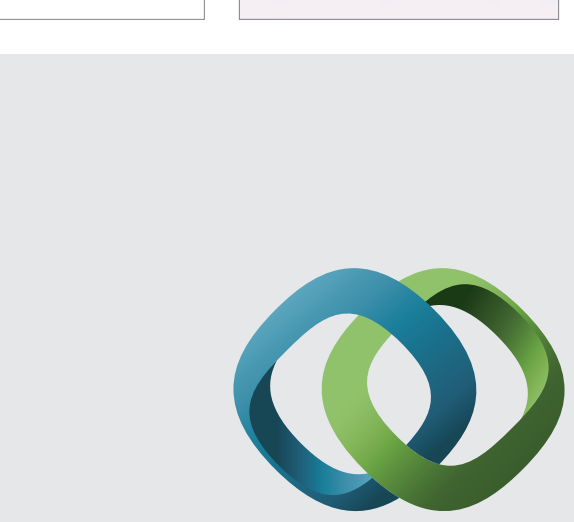

\section{Hindawi}

Submit your manuscripts at

http://www.hindawi.com
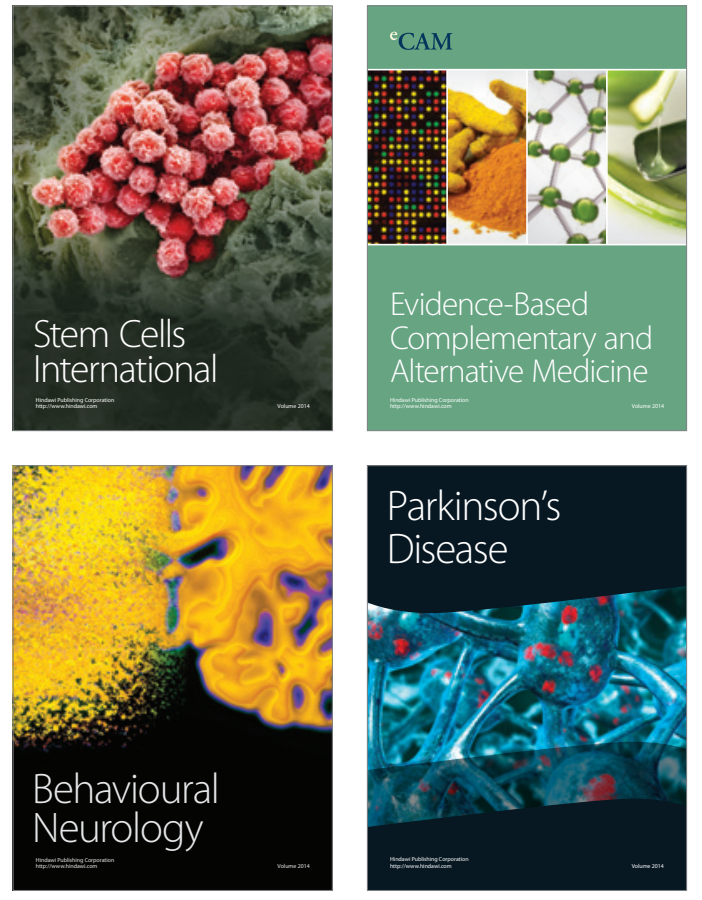
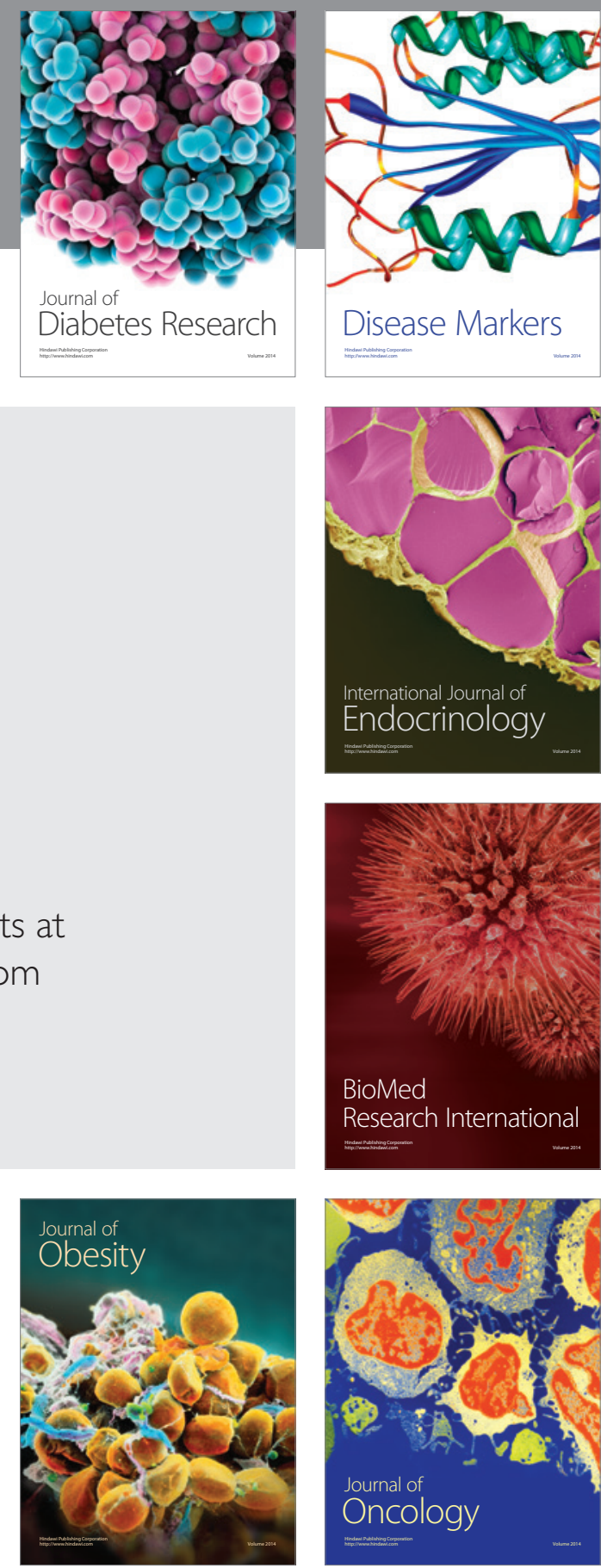

Disease Markers
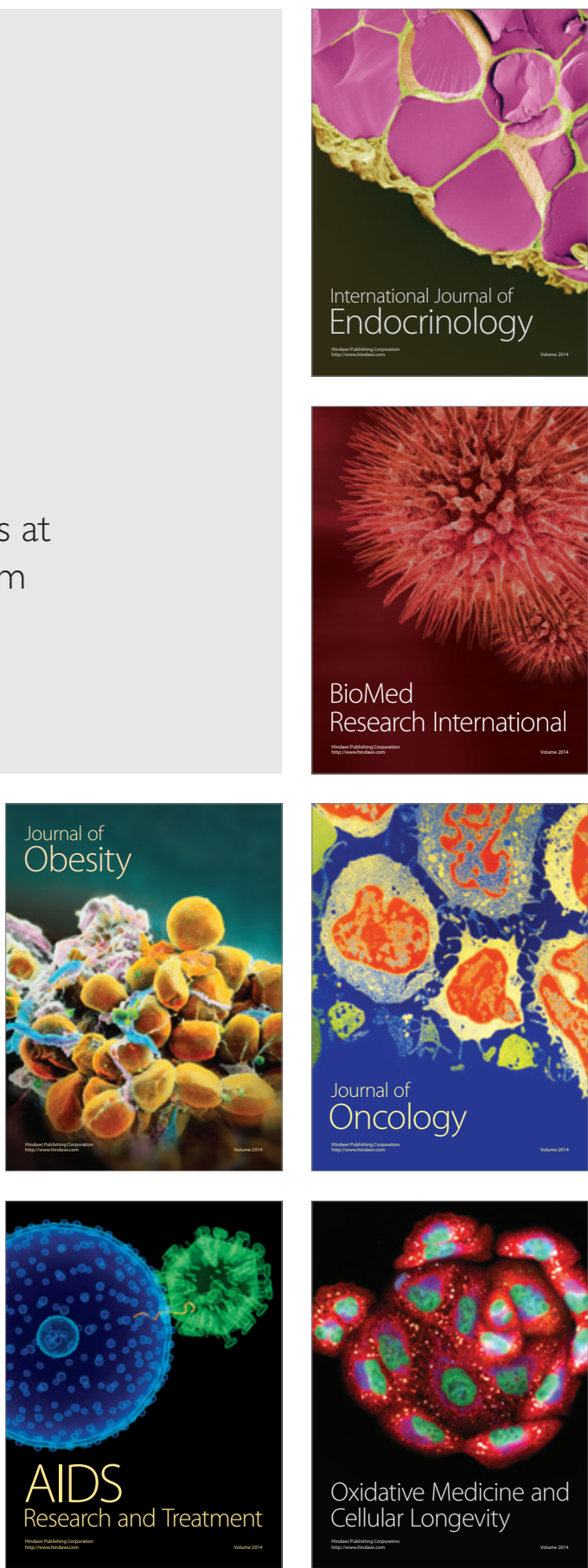